\title{
Bilateral large vestibular aqueduct syndrome in an 11-year-old boy. Radiological and clinical findings
}

\author{
T. Przewoźny ${ }^{1}$, K. Markiet ${ }^{2}$, J. Piątkowski ${ }^{1}$ \\ ${ }^{1}$ Department of Otolaryngology, Medical University of Gdansk, Poland \\ ${ }^{2} 2^{\text {nd }}$ Department of Radiology, Medical University of Gdansk, Poland
}

[Received 10 March 2015; Accepted 28 March 2015]

Clinical observations supplemented with imaging examination show that the large vestibular aqueduct syndrome (LVAS) is a rare developmental anomaly of the inner ear, which leads to hearing loss. The authors present a case history, results of imaging examination (high resolution CT, MRI), results of hearing acuity examinations (tonal audiometry, otoacoustic emissions, brainstem auditory evoked potentials) and results of balance examinations (videonystagmography) in an 11-year-old boy suffering from deep mixed progressive hearing loss of the right ear due to head trauma. The aim of this paper is to specify the most typical clinical, radiological and anatomopathological manifestations of this pathology of the inner ear. The authors describe the diagnostic and identification difficulties associated with the mixed hearing loss observed in this case. The article also discusses the child's activity limitations, which should be taken into account once diagnosis of this rare labyrinthine pathology is established. (Folia Morphol 2015; 74, 2: 265-271)

Key words: large vestibular aqueduct syndrome, hearing loss, congenital inner ear defect

\section{INTRODUCTION}

Large vestibular aqueduct syndrome (LVAS) is characterised by sensorineural hearing loss caused by a malformation of the structures of the inner ear. This is one of the most frequent anomalies of the inner ear, leading to hearing loss in childhood [5, 15, $41,42,46]$. LVAS was first described in 1791 by Carolo Mondini [32] after he carried out a postmortem examination of a temporal bone in a child with congenital deafness. The vestibular aqueduct is a small osseous canal running between the vestibule of the inner ear and the posterior cranial fossa. Inside this canal there is an endolymph duct connecting the elements of the membranous labyrinth with the endolymphatic sac located between the laminas of the dura, at the posterior surface of the petrous pyramid [4, 13, 24, 49]. The function of the canal and the endolymphatic sac has not yet been fully explained. However, it is believed that they maintain a proper composition, volume and osmolality of the fluids in the inner ear [27]. The diameter of the vestibular aqueduct in a healthy person is $0.4-1 \mathrm{~mm}[12,28,49]$, while in patients with LVAS it is at least two times higher $(>1.5 \mathrm{~mm})$ (Fig. 1) [45, 47].

The beginning of the vestibular aqueduct and sac development falls at the end of 4-th week of foetal life. The endolymphatic duct system originates from the dorsomedial part of the auditory vesicle. It invaginates on the medial wall of the labyrinth with its final extension - endolymphatic sac. The endolymphatic

Address for correspondence: Dr T. Przewoźny, Department of Otolaryngology, Medical University of Gdansk, ul. Smoluchowskiego 17 , 80-214 Gdańsk, Poland, tel: +48 5834931 10, fax: +48 5834931 20, e-mail: tprzew@gumed.edu.pl 


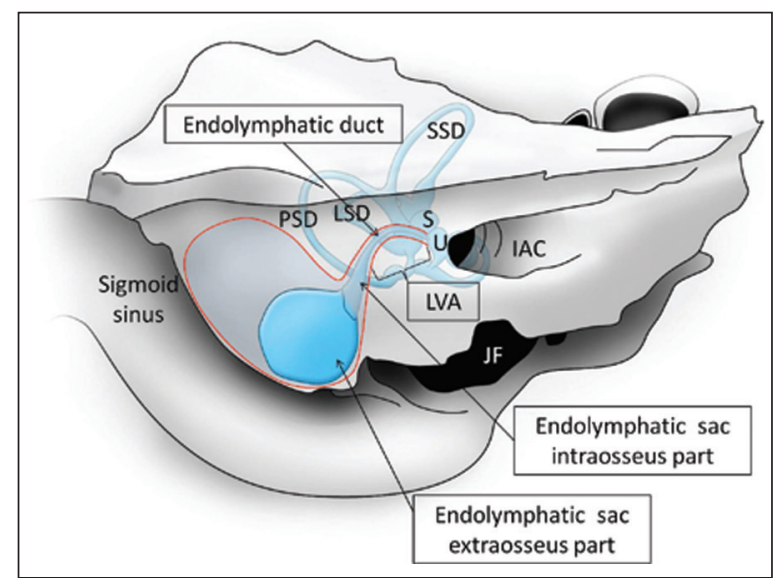

Figure 1. Posterior surface of the left petrous pyramid. Size of a normal vestibular system is marked in blue. Dilated fluid areas of the endolymphatic duct and endolymphatic sac is marked in red; SSD - superior semicircular duct; LSD — lateral semicircular duct; PSD - posterior semicircular duct; U — utricle; S - saccule; IAC — internal auditory canal; JF — jugular foramen; LVA — large vestibular aqueduct.

sac has been reported to continue develop to 3 or 4 years of age $[6,10,21,30]$. Thus, the LVAS is a congenital defect and this is why it usually affects children. However, there are cases of adult onset of symptoms of this syndrome [48]. The prevalence of LVAS amounts to $5-15 \%$ in children with perceptive hearing loss $[28,33,41]$. It is typically manifested by uni- or bilateral hearing loss of a mixed or sensorineural type. Hearing loss usually appears suddenly, and the factors that trigger it include: head injury (fall, strike with a ball), physical exertion, sudden change of pressure (for example during flying a plane) or infection of upper airways [3, 12, 14, 22, 34]. Airbone gap in patients with LVAS can be erroneously interpreted as a disturbance of ventilation of the inner ear or stiffening of the ossicular chain, having a similar clinical course to otosclerosis. Decreased mobility of the stapes in these patients is actually caused by excessive pressure of the perilymph [15]. Another important symptom of LVAS is vertigo. In children it is described as coordination disturbances and instability. Its prevalence is estimated at $30 \%$ of cases $[17,22,35,38]$. LVAS in adults rarely causes vertigo. Diagnosis of LVAS is made based on imaging examinations of the inner ear: computer tomography (CT) and magnetic resonance imaging (MRI) $[2,7$, $25,40]$. Assessment of vestibular aqueduct using MRI is more efficient and gives fewer falsely negative results compared to $C T[11,20,37]$. So far, no method of effective treatment of LVAS has been discovered.
Some authors recommend treatment with steroids, but there are no clinical trial results to convincingly confirm its effectiveness [18]. There are reports of hyperbaric oxygen therapy application [43]. There have been attempts to treat this defect of the inner ear with surgical methods, for example by drainage of the endolymphatic sac, but they turned out to be ineffective [22]. In case of fluctuating or progressive hearing loss, one of the possible solutions is providing the patient with a hearing aid. If the illness leads to bilateral deafness, the only effective method of treatment is the cochlear implant $[9,19]$. During cochlear implantation in patients with LVAS it should be taken into account that an intensive outflow of perilymph can be encountered after cochleostomy (gusher) [23, 44]. It is crucial for the therapy to inform the patient that it is necessary that he or she avoids head injuries and contact sports (football, hockey, wrestling, martial arts, skate board jumping, etc.) $[8,26]$. LVAS can occur in isolation, in complexes of defects such as Pendred syndrome, branchio-oto-renal syndrome, or can even be familial (therefore in some patients genetic consultation is recommended) $[1,16,36,50]$.

\section{CASE REPORT}

The 11-year-old boy was referred to the Audiological Outpatient Department of the University Clinical Centre by a paediatrician due to hearing loss in the right ear. According to the boy's mother, 13 months earlier the child suffered from head injury resulting from a fall from $2.5 \mathrm{~m}$ when the boy was playing (fall from the roof of a garage onto a hard surface). After the accident the child was not examined in any medical entity, had a bruising of the right shoulder and head in the right fronto-temporal area and did not complain of any problems with hearing. After 4 months the boy started complaining of hearing loss in the right ear which appeared suddenly after he got up from bed. There was no concomitant tinnitus or dizziness. The mother reported to a company offering hearing aids, where tonal audiometry revealed a typical conductive hearing loss in the right, type $B$ tympanometry and lack of the right stapedial muscle reflex. Moreover, low-tone conductive hearing loss of the left ear was diagnosed of a mild degree. Examination of hearing was repeated after a month in a district otolaryngological department. It showed closure of air-bone gap for frequency $0.125-1 \mathrm{kHz}$ and lack of improvement of hearing at frequency $2-8 \mathrm{kHz}$ in the right ear with a normal curve for bone 
conduction. Normal result of the tympanometric examination was observed (however there were still no reflex from the right stapedial muscle) and a decrease of conductive low-tone hearing loss in the left ear. The child was treated conservatively with intranasal steroids but with no subjective improvement of hearing. After another 4 months the mother ordered a second tonal audiometry in a different company on her own initiative. The examination revealed presence of moderately severe mixed hearing loss and low-tone hearing loss of the left ear (bone conduction curve examination was not carried out). The child was referred to the audiological outpatient department of the district military hospital. The tonal audiometry performed in the hospital again showed a typical conductive hearing loss of moderate severity of the right ear and mild hearing loss of the left ear. The MRI was performed and bilateral widening of the vestibular aqueduct was found, manifested as cystic lesions in a typical location, to $3.7 \mathrm{~mm}$ at the right side and $3.2 \mathrm{~mm}$ at the left side. Nerve VII and VIII complexes were symmetric with no evidence of thickening. A radiological diagnosis of bilateral dilation of vestibular aqueducts was made (LVAS) (Figs. 2-4).

The child still did not present with improvement of right ear hearing loss. Audiometric examination was repeated, which did not show change as regards the severity and conductive type of the hearing loss. In the same paediatric hospital high resolution CT examination of temporal bones was performed using spiral protocol in $0.625 \mathrm{~mm}$ layers. It revealed normal picture of temporal bones. Brainstem auditory evoked potentials examination revealed objective hearing threshold of the right ear $=80 \mathrm{dBnHL}$ and normal hearing threshold of the left ear $=5 \mathrm{dBnHL}$. Result of functional examination of the vestibular system - videonystagmography (VNG) was normal. At the mother's request the boy was referred to the Audiological Outpatient Department of the University Clinical Centre for further diagnostic assessment and treatment. During the first visit medical history was collected from the patient (described above). Mother's first pregnancy, first labour, at term, natural and spontaneous labour, APGAR 9. The course of pregnancy was non-complicated. The child was vaccinated according to the standard vaccination schedule. Underwent several typical infections of upper airways in early childhood. He was rarely ill, never operated on. At the age of 6 , allergy to grasses,

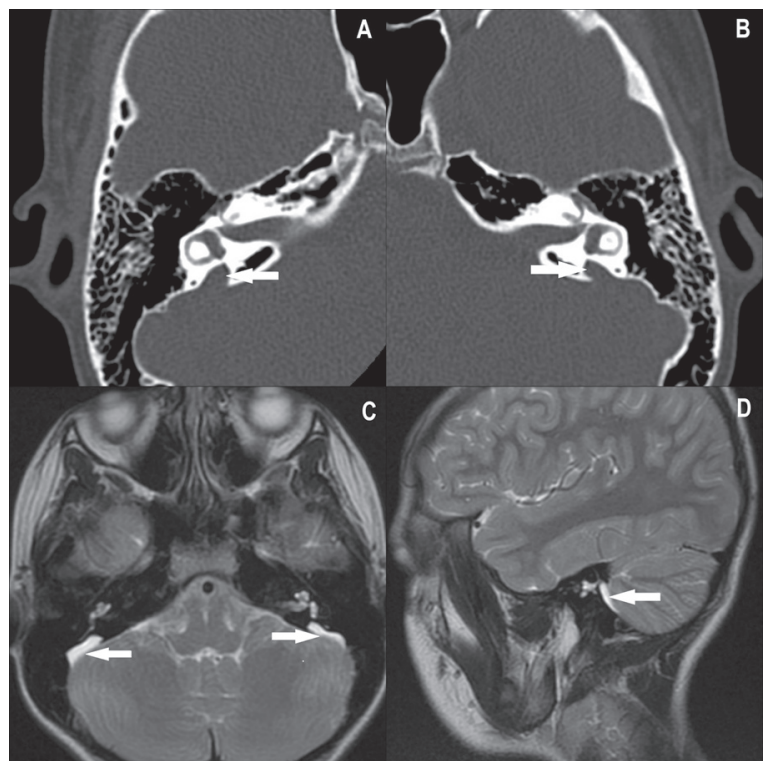

Figure 2. 11-year-old patient presenting bilateral changes in the course of large vestibular aqueduct syndrome (LVAS). High resolution computed tomography (HRCT) axial image (A) shows enlarged right vestibular aqueduct (arrow). Axial HRCT image (B) - enlarged vestibular aqueduct (arrow) on the left. Axial T2-weighted magnetic resonance image (MRI) (C) shows bilateral saccular enlargement of endolymphatic sacs (arrows). Sagittal T2-weighted MRI (D) - enlarged endolymphatic sac on the left (arrow). Note that no accompanying abnormalities are seen.

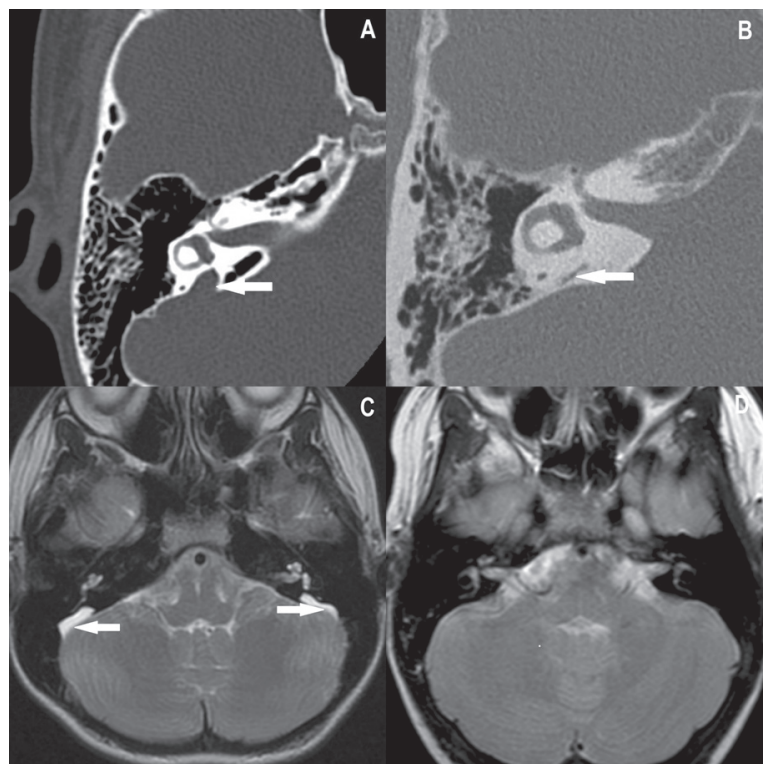

Figure 3. High resolution computed tomography axial image (A) shows enlarged right vestibular aqueduct (arrow). The arrow shows a normal vestibular aqueduct in a healthy individual (B). Axial T2-weighted magnetic resonance image (MRI) (C) shows bilateral saccular enlargement of endolymphatic sacs (arrows). Note that no accompanying abnormalities are visible. Axial T2-weighted MRI (D) in a healthy patient. 


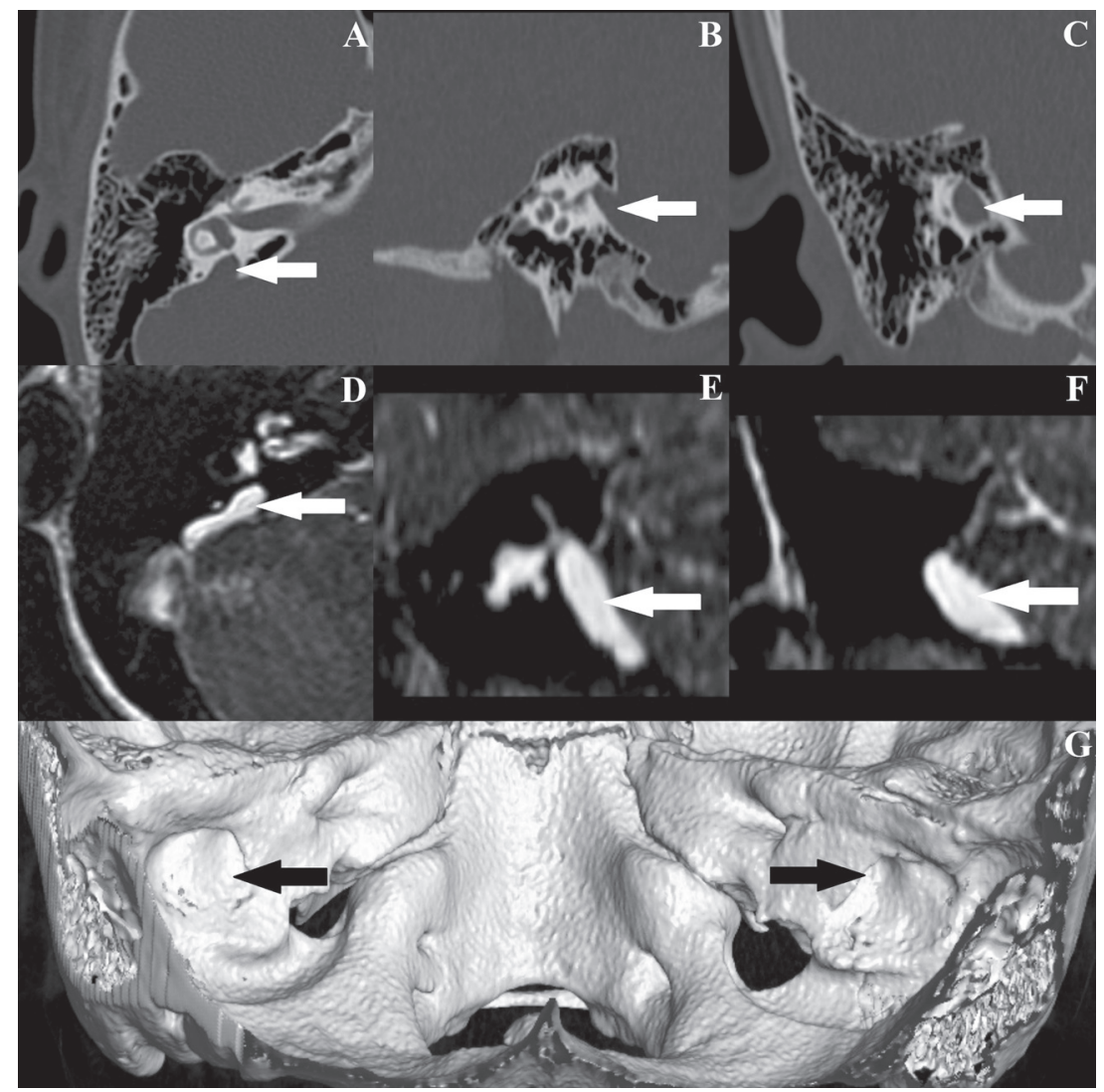

Figure 4. High resolution computed tomography axial image $(\mathbf{A})$ and multiplanar reconstructions in sagittal (B) and coronal (C) planes show right enlarged vestibular aqueduct (arrows). Corresponding magnetic resonance T2-weighted images in axial (D), sagittal (E) and coronal (F) planes - enlarged endolymphatic sac on the right (arrow). Computed tomography, 3-dimensional reconstruction of posteromedial surfaces of both temporal bones $(\mathbf{G})$ - arrows point at bilaterally enlarged vestibular aqueducts.
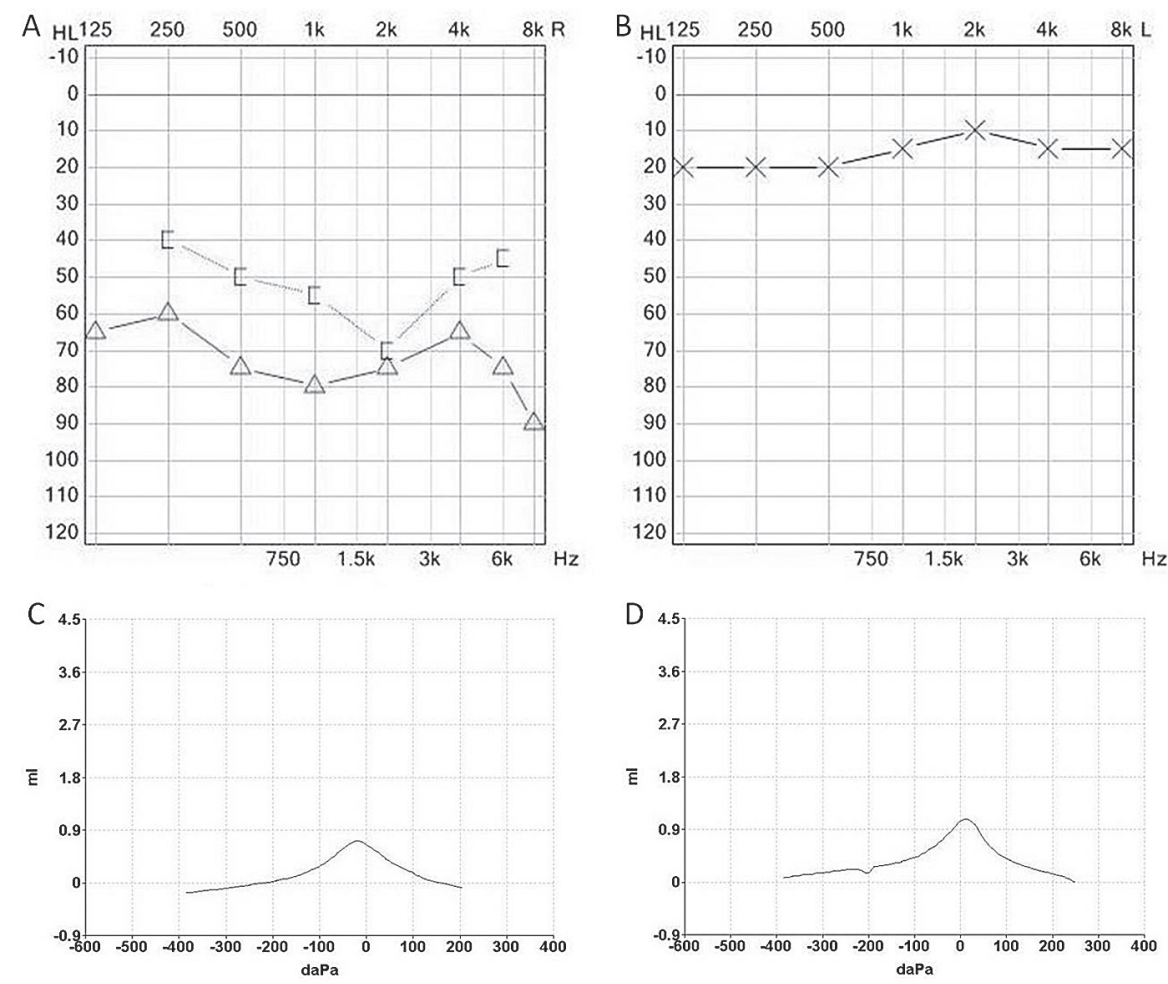

Figure 5. Results of hearing examinations in a 11-year-old boy with bilateral large vestibular aqueduct syndrome (LVAS). Tonal audiogram (A), unilateral severe mixed hearing loss in the right ear. Normal hearing in the left ear with asymptomatic LVAS (B). Normal result of tympanometry of the right (C) and left ear (D). $\Delta, \times-$ air conduction; [ - bone conduction. 
grains, moulds and birch pollen was diagnosed. He took periodically oral antihistaminic medications. He currently attends the fifth class of primary school. He had no significant educational problems. Development of speech and language adequate to age. Family history of hearing loss or syndromes associated with congenital defects of the the facial skeleton was negative. Otolaryngological examination of the ears, nose, naso- and oropharynx, larynx and neck revealed no abnormalities. The child underwent a number of audiological tests. The tonal audiometry revealed righ-sided severe mixed hearing loss, normal tympanometry, no ipsilateral stapedial reflex on the right and contralateral on the left side and no otoacoustic emissions in the right ear (Fig. 5).

The conducted examinations confirmed the presence of mixed hearing loss in the right ear with prevalent sensorineural component (over the conductive one), of cochlear aetiology, normal compliance of tympanic membrane and lack of ipsilateral reflex from the right stapedial muscle. Based on radiological examination, medical history, clinical examination and audiological tests diagnosis of bilateral large vestibular aqueduct syndrome (clinically manifested at the right side) was confirmed. The patient's mother was informed about the nature of illness and the risk of a total hearing loss. The mother and the boy were informed that it is strictly forbidden for him to practise contact sports or any other that may cause sudden irregular increases of cerebrospinal fluid pressure, such as diving, sports at height, parachuting. The boy was instructed to pay special attention to prevent head injuries when playing. The mother was informed about the possibilities of providing the boy with hearing aid or cochlear implant if hearing loss develops in the only hearing ear. A cycle of follow-up visits was planned with regular examination of hearing every 3 months in the Audiological Outpatient Department of the University Clinical Centre. The child remains under constant clinical observation due to the risk of gradual progression of bilateral total hearing loss.

\section{DISCUSSION}

Presented case is a typical clinical example of LVAS in a child. Diagnosis of this illness most frequently pertains to children at nursery school or school age. Santos et al. [42] described 55 children with LVAS at the age of 6 months to 11 years (mean 4 years), while Saliba et al. [41] reported age range between 13 months and 15 years (mean 5.9 years). Our patient was in the upper age limit. There is no explicit data as regards sex predilection of patients with LVAS. It could seem logical that the syndrome more frequently affects boys, since they are more prone to injuries at this age. However, LVAS is more frequently diagnosed in girls. In the summary made by Madden et al. [28] describing 77 patients, the male to female ratio was 1:1.5. Similar value was reported by Jackler and De La Cruz (1:2) and Saliba et al. $(2: 3)[22,41]$. Santos et al. [42] did not show sex predilection for the syndrome described. Prevalence of bilateral LVAS is definitely higher than that of the unilateral one and amounts to $67-85 \%$ of all cases $[5,42]$. Different values were provided by Saliba et al. [41], who estimated the prevalence of unilateral enlarged vestibular aqueduct at $57.5 \%$. Our case is non-typical due to the unilateral severe hearing loss at bilateral developmental defect of the inner ear. In the work by Santos et al. [42] among 55 patients with LVAS, who underwent detailed analysis of the hearing organ, there were no cases like our case.

Diagnosis of LVAS is usually made based on radiological measurements of the diameter of the vestibular aqueduct, which at the half of the distance between crus common and operculum of the aqueduct should be of at least $1.5 \mathrm{~mm}$ and at least $2 \mathrm{~mm}$ in the area of the operculum $[45,47]$. In our patient these measures were $3.7 \mathrm{~mm}$ and $3.2 \mathrm{~mm}$, respectively for the right and left ear, which fulfilled the diagnostic criteria. Some authors described an even greater dilation of the vestibular aqueduct - to $6 \mathrm{~mm}$, suggesting that there is a relation between the diameter of the aqueduct and the severity of hearing loss [22, 41, 51]. The case described by us did not fully confirm this relation due to normal auditory thresholds in the other ear - also having a dilated aqueduct. Our patient presented with unilateral psudo-conductive hearing loss, which significantly hindered establishing the final diagnosis. Literature describes similar diagnostic difficulties [29, 31]. Interestingly enough, normal result of tympanometry was observed in the ear with pseudocondcutive hearing loss, as well as presence of contralateral reflex from the stapedial muscle, indicating normal mobility of the ossicular chain. Such a configuration of results of audiometric examination suggests presence of sensorineural hearing loss rather than a mixed or conductive one. A very similar case was described by Dipak et al. [14], in a 6-year-old girl, who primarily had severe mixed hearing loss, which evolved into a sensorineural loss 
within a month. Similar observations were made by Madden et al. [28], who diagnosed pseudoconductive hearing loss at low frequencies and normal tympanogram in $28 \%$ of their subjects. There are reports of cases in which explorative tympanotomy was conducted unnecessarily in patients with LVAS, who during the procedure were found to have normal mobility of the ossicular chain [15]. No otoacoustic emissions in the ear affected with such a deep hearing loss as in the case of our patient does not have localising value. All hearing losses of more than 40 $\mathrm{dBHL}$ in the speech band cause a $90 \%$ probability of otoacoustic emissions disappearance [39]. LVAS can occur in complexes of congenital defects associated with hearing loss. Negative family history and lack of clinical signs of congenital defects in our patient did not suggest such aetiology. Electrophysiological examination of hearing ruled out the presence of extracochlear hearing disturbances, which are not characteristic for LVAS. Despite bilateral involvement of the vestibular system, our patient did not report any dizziness. VNG did note reveal asymmetry of caloric excitability of the labyrinths in this patient. Similar observations were made by Jackler and De La Cruz [22], who carried out electronystagmography in 2 out of 17 patients with LVAS and did not find signs of asymmetry. Life activity of patients with LVAS is limited by the necessity to behave cautiously in order to prevent sudden increase of cerebrospinal fluid pressure, which causes irregular aggravation of hearing. As reported by some authors, there is high probability that our patient will develop bilateral hearing loss $[14,52]$. This is why it is so important to maintain continuous audiological observation and inform the parents of children with LVAS about the hearing aids or advanced implantation techniques.

\section{CONCLUSIONS}

The clinical picture of LVAS in children is not explicit and frequently causes many diagnostic and therapeutic difficulties. Our patient was initially diagnosed with a typical conductive hearing loss and disturbances of middle ear ventilation was suspected to be the cause of the disease. Based on the results of conducted examination, otosclerosis could be suspected as well. The changeable clinical picture of the illness (alternating diagnosis of conductive and mixed hearing loss) forced the clinicians to carry out head MRI which revealed presence of bilateral congenital defect of the inner ear - both in the ear with hearing loss and the normally-hearing ear. Other examinations confirmed unilateral mixed hearing loss with mild conductive component, most probably caused by increased pressure of perilymph, which resulted in initial diagnostic difficulties. Therefore, in every child with severe mixed hearing loss of unstable intensity and unknown cause, imaging examinations of the brain and temporal bones should be performed. An extremely important clinical aspect of the presented case is the prevention of hearing loss in the other, the only properly hearing ear. In the case of unilateral LVAS it is not really important. However, in the bilateral syndrome, if bilateral total loss of hearing has not yet occurred, prevention based on decreasing the risk of head injuries to the minimum is of crucial importance.

\section{REFERENCES}

1. Albert $S$, Blons $H$, Jonard $L$, Feldmann $D$, Chauvin $P$, Loundon N, Sergent-Allaoui A, Houang M, Joannard A, Schmerber S, Delobel B, Leman J, Journel H, Catros H, Dollfus H, Eliot MM, David A, Calais C, Drouin-Garraud V, Obstoy MF, Tran Ba Huy P, Lacombe D, Duriez F, Francannet C, Bitoun P, Petit C, Garabédian EN, Couderc R, Marlin S, Denoyelle F (2006) SLC26A4 gene is frequently involved in nonsyndromic hearing impairment with enlarged vestibular aqueduct in Caucasian populations. Eur J Hum Genet, 14: 773-779.

2. Antonelli P, Varela A, Mancuso A (1999) Diagnostic yield of high-resolution computer tomography for pediatric sensorineural hearing loss. Laryngoscope, 109: 1642-1647.

3. Arcand P, Desrosiers M, Dubé J, Abela A (1991) The large vestibular aqueduct syndrome and sensorineural hearing loss in the pediatric population. J Otolaryngol, 20: 247-250.

4. Arenberg IK, Dupatocinio I, Dreisbach JM, Seibert C (1984) Radiographic classification of the vestibular and cochlear aqueducts: the paired correlation between normal and abnormal vestibular aqueduct and cochlear aqueduct anatomy. Laryngoscope, 94: 1325-1333.

5. Atkin JS, Grimmer JF, Hedlund G, Park AH (2009) Cochlear abnormalities associated with enlarged vestibular aqueduct anomalny. Int J Pediatr Otorhinolaryngol, 73: 1682-1685. doi: 10.1016/j.ijporl.2009.08.028.

6. Bagger-Sjöbäck D (1991) Embryology of the human endolymphatic duct and sac. ORL J Otorhinolaryngol Relat Spec, 53: 61-67.

7. Becker TS, J Vignaud, A Sultan, M Lachman (1983) The vestibular aqueduct in congenital deafness: evaluation by the axial projection. Radiology, 149: 741-744.

8. Boston M, Halsted M, Meinzen-Derr J, Bean J, Vijayasekaran S, Arjmand E, Choo D, Benton C, Greinwald J (2007) The large vestibular aqueduct: a new definition based on audiologic and computed tomography correlation. Otolaryngol Head Neck Surg, 136: 972-977.

9. Chen X, Liu B, Liu S, Mo L, Liu H, Dong R, Li Y, Gong S, Han D, Zhang $L$ (2011) The development of auditory skills in infants with isolated large vestibular aqueduct syndrome after cochlear implantation. Int J Pediatr Otorhinolaryngol, 75: 943-947. doi: 10.1016/j.ijporl.2011.04.015.

10. Bagger-Sjöbäck D, Lundberg AM (1990) Developmental aspects of the human endolymphatic sac. Acta Otolaryngol Suppl, 470: 51-55.

11. Davidson $H$, Harnsberger HR, Lemmerling MM, Mancuso AA, White DK, Tong KA, Dahlen RT, Shelton C (1999) MR eva- 
luation of vestibulocochlear anomalies associated with large endolymphatic duct and sac. Am J Neuroradiol, 20: $1435-1441$.

12. Dewan K, Wippold FJ, Lieu JE (2009) Enlarged vestibular aqueduct in pediatric SNHL. Otolaryngology Head and Neck Surgery, 140: 552-558.

13. Dimopoulos PA, Smedby O, Wilbrand HF (1996) Anatomical variations of the human vestibular aqueduct. Part I. A radioanatomical study. Acta Radiol Suppl, 403: 21-32.

14. Dipak S, Prepageran N, Sazila AS, Rahmat O, Raman R (2005) Large vestibular aqueduct syndrome. Med J Malaysia, 60: 489-491.

15. Govaerts PJ, Casselman J, Daemers K, De Ceulaer G, Somers T, Offeciers FE (1999) Audiological findings in large vestibular aqueduct syndrome. Int J Pediatr Otorhinolaryngol, 51: 157-164.

16. Griffith A, Arts A, Downs C, Innis JW, Shepard NT, Sheldon S, Gebarski SS (1996) Familial large vestibular aqueduct syndrome. Laryngoscope, 106: 960-965.

17. Grimmer JF, Hedlund G (2007) Vestibular symptoms in children with enlarged vestibular aqueduct anomaly. Int J Pediatr Otorhinolaryngol, 71: 275-282.

18. Grimmer JF, Hedlund G, Park A (2008) Steroid treatment of hearing loss in enlarged vestibular aqueduct anomaly. Int J Pediatr Otorhinolaryngol, 72: 1711-1715.

19. Harker LA, Vanderheiden S, Veazey D, Gentile N, McCleary E (1999) Multichannel cochlear implantation in children with large vestibular aqueduct syndrome. Ann Otol Rhinol Laryngol Suppl, 177: 39-43.

20. Harnsberger HR, Dahlen RT, Shelton C, Gray SD, Parkin JL (1995) Advanced techniques in magnetic resonance imaging in the evaluation of the large endolymphatic duct and sac syndrome. Laryngoscope, 105: 1037-1042.

21. Hultcrantz M, Bagger-Sjöbäck D, Rask-Andersen H (1987) The development of the endolymphatic duct and sac. A light microscopical study. Acta Otolaryngol, 104: 406-416.

22. Jackler RA, De La Cruz A (1989) The large vestibular aqueduct syndrome. Laryngoscope, 99: 1238-1242.

23. Kim BG, Sim NS, Kim SH, Kim UK, Kim S, Choi JY (2013) Enlarged cochlear aqueducts: a potential route for CSF gushers in patients with enlarged vestibular aqueducts. Otol Neurotol, 34: 1660-1665. doi: 10.1097/ /MAO.0b013e3182a036e4

24. Kodama A, Sando I (1982) Dimensional anatomy of the vestibular aqueduct and the endolymphatic sac (rugose portion) in human temporal bones. Statistical analysis of 79 bones. Ann Otol Rhinol Laryngol Suppl, 96: 13-20.

25. Koesling S, Rasinski C, Amaya B (2006) Imaging and clinical findings in large endolymphatic duct and sac syndrome. Eur J Radiol, 57: 54-62.

26. Levenson MJ, Parisier SC, Jacobs M, Edelstein DR (1989) The large vestibular aqueduct syndrome in children. A review of 12 and the description of a new clinical entity. Arch Otolaryngol Head Neck Surg, 115: 54-58.

27. Linthicum FH Jr, Doherty J, Webster P, Makarem A (2014) The periductal channels of the endolymphatic duct, hydrodynamic implications. Otolaryngol Head Neck Surg, 150: 441-447. doi: 10.1177/0194599813516420.

28. Madden A, Halsted M, Benton C, Greinwald J, Choo D (2003) Enlarged vestibular aqueduct syndrome in the pediatric population. Otol Neurotol, 24: 625-632.

29. Mafee MF, Charletta D, Kumar A, Belmont H (1992) Large vestibular aqueduct and congenital sensorineural hearing loss. Am J Neuroradiol, 13: 805-819.

30. Ng M, Linthicum FH (1998) Morphology of the developing human endolymphatic sac. Laryngoscope, 108: 190-194.

31. Merchant SN, Nakajima HH, Halpin C, Nadol JB Jr, Lee DJ, Innis WP, Curtin H, Rosowski JJ (2007) Clinical investigation and mechanism of air-bone gaps in large vestibular aqueduct syndrome. Ann Otol Rhinol Laryngol, 116: 532-541.

32. Mondini C (1997) Minor works of Carlo Mondini: the anatomical section of a boy born deaf. Am J Otol, 18: 288-293.

33. National Institute on Deafness and Other Communication Disorders (NIDCD). Enlarged vestibular aqueducts and childhood hearing loss. available at: www.nidcd.nih.gov/ health/hearing/eva.asp.

34. Noordman BJ, van Beeck Calkoen E, Witte B, Goverts T, Hensen E, Merkus P (2015) Prognostic factors for sudden drops in hearing level after minor head injury in patients with an enlarged vestibular aqueduct: a meta-analysis. Otol Neurotol, 36: 4-11. doi: 10.1097/ /MAO.0000000000000659.

35. Oh AK, Ishiyama A, Baloh RW (2001) Vertigo and the enlarged vestibular aqueduct syndrome. J Neurol, 248: 971-974.

36. Okamoto $Y$, Mutai $H$, Nakano A, Arimoto $Y$, Sugiuchi T, Masuda S, Morimoto N, Sakamoto H, Ogahara N, Takagi A, Taiji H, Kaga K, Ogawa K, Matsunaga T (2014) Subgroups of enlarged vestibular aqueduct in relation to SLC26A4 mutations and hearing loss. Laryngoscope, 124: 134-140. doi: 10.1002/lary.24368.

37. Okamoto K, Ito J, Furusawa T, Sakai K, Tokiguchi S (1997) Large vestibular aqueduct syndrome with high $\mathrm{CT}$ density and high MR signal intensity. Am J Neuroradiol, 18: 482-484.

38. Okumura T, Takahashi H, Honjo I, Takagi A, Mitamura K (1995) Sensorineural hearing loss in patients with large vestibular aqueduct. Laryngoscope, 105: 289-293.

39. Robinette MS (2003) Clinical observations with evoked otoacoustic emissions at Mayo Clinic. J Am Acad Audiol, 14: 213-224.

40. Robson CD (2006) Congenital hearing impairment. Pediatr Radiol, 36: 309-324.

41. Saliba I, Gingras-Charland ME, St-Cyr K, Décarie JC (2012) Coronal CT scan measurements and hearing evolution in enlarged vestibular aqueduct syndrome. Int J Pediatr Otorhinolaryngol, 76: 492-499. doi: 10.1016/j. ijporl.2012.01.004.

42. Santos S, Sgambatti L, Bueno A, Albi G, Suárez A, Domínguez MJ (2010) Enlarged vestibular aqueduct syndrome. A review of 55 paediatric patients. [Article in Spanish]. Acta Otorrinolaringol Esp, 61: 338-344. doi: 10.1016/j. otorri.2010.04.002

43. Shilton H, Hodgson M, Burgess G (2014) Hyperbaric oxygen therapy for sudden sensorineural hearing loss in large vestibular aqueduct syndrome. J Laryngol Otol Suppl, 128: 50-54. doi: 10.1017/S0022215113001308.

44. Shirazi A, Fenton JE, Fagan PA (1994) Large vestibular aqueduct syndrome and stapes fixation. J Laryngol Otol, 108: 989-990.

45. Swartz JD, Yussen PS, Mandell DW (1985) The vestibular aqueduct syndrome: computed tomographic appearance. Clin Radiol, 36: 241-243.

46. Valvassori GE (1983) The large vestibular aqueduct and associated anomalies of the inner ear. Otolaryngol Clin North Am, 16: 95-101.

47. Valvassori GE, Clemis JD (1978) The large vestibular aqueduct syndrome. Laryngoscope, 88: 723-728.

48. Wieczorek SS, Anderson ME Jr, Harris DA, Mikulec AA (2013) Enlarged vestibular aqueduct syndrome mimicking otosclerosis in adults. Am J Otolaryngol, 34: 619-625. doi: 10.1016/j.amjoto.2013.07.015.

49. Wilbrand HF, Rask-Andersen H, Gilstring D (1974) The vestibular aqueduct and the para-vestibular canal. An anatomic and roentgenologic investigation. Acta Radiol Diagn (Stockh), 15: 337-355.

50. Yuan Y, Guo W, Tang J, Zhang G, Wang G, Han M, Zhang X, Yang S, He DZ, Dai P (2012) Molecular epidemiology and functional assessment of novel allelic variants of SLC26A4 in non-syndromic hearing loss patients with enlarged vestibular aqueduct in China. PLoS One, 7: e49984. doi: 10.1371/journal.pone.0049984.

51. Zalzal GH, Tomaski SM, Vezina LG, Bjornsti P, Grundfast KM (1995) Enlarged vestibular aqueduct and sensorineural hearing loss in childhood. Arch Otolaryngol Head Neck Surg, 121: 23-28.

52. Żarowski A, Skarżyński H, Skarżyńka B, Miszka K (2000) Progressive hearing loss caused by an enlarged vestibular aqueduct: large vestibular aqueduct syndrome (LVAS). [Article in Polish]. Audiofonologia, 18: 187-194. 